\title{
$\mathrm{KL}-510$ 히중모형을 적용한 강합성 2거더교 $\mathrm{RC}$ 장지간 바닥판의 최소두께
}

\author{
박우진 · 황훈희 ${ }^{\dagger \star}$ \\ 서일대학교 토목과 - ${ }^{*}$ 한국도로교통협회 기술국
}

(2014. 4 29. 접수 / 2014. 6. 11. 채택)

\section{Minimum Thickness of Long Span RC Deck Slabs for Composite 2-girder Bridges Designed by KL-510 Load Model}

\author{
Woo-Jin Park $\cdot$ Hoon-Hee Hwang ${ }^{\dagger \star}$ \\ Department of Civil Engineering, Seoil University $\cdot{ }^{*}$ Korea Road \& Transportation Association
}

(Received April 29, 2014 / Accepted June 11, 2014)

\begin{abstract}
The minimum thickness of long-span deck slab is proposed by checking the limit state according to the Korean highway bridge design code(limit state design). Both minimizing thickness and ensuring safety of deck slab are important design factors to increase a competitive price of the long span deck slabs. The required thicknesses for satisfying flexural capacity, preventing punching shear failure and limiting deflection were calculated by considering KL-510 load model which has increased total load compared to DB 24 from $432 \mathrm{kN}$ to $510 \mathrm{kN}$. The results of the required thickness for various limit states were compared to propose the minimum thickness as a function of span length of deck slabs. The proposed minimum thickness is influenced by satisfying flexural capacity and limiting deflection. It turns out to be similar compared to the results of the previous study by ultimate strength design method even if the live load model was increased in total weights.
\end{abstract}

Key Words : minimum thickness, KL-510, limit state design, long span bridge deck, RC deck

\section{1. 서 론}

국토교통부에서는 보다 합리적인 교량설계를 위하 여 도로교설계기준(한계상태설계법)을 제정하였으며, 2015년부터 적용을 예고하였다 ${ }^{1)}$. 이 설계기준에서는 활하중 모델로서 KL-510 하중을 새롭게 도입하였다. 이는 기존 도로교설계기준 ${ }^{2}$ 에 규정된 $\mathrm{DB}$ 하중을 대체 하는 것으로서 국내 중차량의 통행 특성을 실측하고 분석한 연구결과 ${ }^{3-4}$ 로부터 제시되었으며, 차륜의 최대 하중 크기는 동일하지만 차축의 수가 늘어나 총하중이 증가되었다. 또한 새로운 설계개념의 도입에 따라 한 계상태별로 하중조합, 하중계수 등을 적용하는 등 규 정의 변화도 설계 결과에 영향을 미치게 될 것으로 예 상된다.

하중효과는 구조물에 요구되는 성능을 결정하기 위 한 가장 기본적인 요소이다. 실무 설계에 있어서 하중 효과는 설계기준에서 제시하는 하중모델과 재하방법
등의 설계절차에 따라 결정된다. 그러므로 교량의 바 닥판과 같이 하중에 직접적으로 접하여 지지하는 부재 는 하중모델의 변화에 따르는 면밀한 검토가 요구된다. 특히, 명확한 규정이 제시되어 있지 않은 장지간 바닥 판의 경우에는 더욱 그러하다.

장지간 바닥판은 강합성 2 거더교와 같이 거더수를 최소화하기 위해 거더 간격을 넓게 배치하는 소수거더 교 등 지간이 넓은 구조물을 주요 적용 대상으로 하므 로 고정하중의 증가를 억제하는 것이 경쟁력을 결정짓 는 중요한 요소이다. 따라서 지간에 대한 두께 비가 낮 게 설계되어야 하므로 안전성과 사용성을 확보할 수 있는 최소두께의 결정이 매우 중요한 설계요소이다. 이러한 중요성으로 인하여 철근콘크리트 바닥판과 프 리스트레스트콘크리트 바닥판을 대상으로 지간에 따 른 바닥판 최소두께식이 제안되었다 ${ }^{5-7)}$. 또한 장지간화 에 따른 파괴형태와 선행연구에서 제안된 최소두께식 의 검증을 위한 실험 및 해석적 연구도 수행되었다 ${ }^{8-10)}$.

† Corresponding Author :Hoon-Hee Hwang, Tel : +82-02-3490-1041, E-mail : poonhee@krta.co.kr

Korea Road \& Transportation Association, 805, DaewangPangyoro, Sujeong-gu, Seongnam-si,, Gyeonggi-do, Korea, 461-703 
그러나 이러한 연구결과는 강도설계법을 기반으로 도출되었으므로 새롭게 시행되는 도로교설계기준(한계 상태설계법)에 따른 재검토가 반드시 필요하다. 특히, $\mathrm{KL}-510$ 하중은 $\mathrm{DB}$ 하중에 비해 총하중이 증가되었으 므로 활하중 모델의 변화를 고려한 검토는 구조물의 안전을 확보하기 위한 측면에서 매우 중요하다.

이 연구에서는 가장 일반적인 형태인 철근콘크리트 바닥판을 대상으로 선행연구에서 제시된 장지간 바닥 판의 최소두께 제안식이 새로운 활하중모델과 한계상 태설계법 기반의 제반 규정에 대해서 적정성과 유효성 을 유지할 수 있는지 검토하였으며, 이로써 수정된 최 소두께식을 제안하였다.

\section{2. 해석 모델}

하중효과를 예측하기 위하여 유한요소해석을 수행 하였다. 이 때 도로교설계기준(한계상태설계법)에 따른 하중모델 및 재하방법 등을 적용하였으며, 강도설계법 에 기반한 선행 연구 결과와와의 비교를 위해 가능한 동일한 유한요소와 경계 조건을 사용하는 등 유사한 조건을 갖는 해석 모델을 구성하였다. 따라서 바닥판 은 4절점을 가지는 Plate요소를 사용하였으며, 2개의 거더축을 따라 단순지지된 유한요소모델에 대해 영향 면 해석을 수행하여 하중효과에 의한 최대모멘트, 최 대전단력과 최대처짐값을 결정하였다(Fig. 1). 이 때 적 용된 KL-510 하중 모형은 기존 하중모형인 DB 24와 비교하여 최대 축중은 $192 \mathrm{kN}$ 으로 동일하나 중간축의 수가 2개로 증가되어 총 4축으로 구성되었으며, 이에 따라 총중량은 $510 \mathrm{kN}$ 으로서 약 $18 \%$ 정도 증가되었다 (Fig. 2).

한계상태에 대한 하중조합은 극한 I, 사용 П를 적용 하였으며, 바닥판 지간이 늘어나면 재하차로 수가 증 가되므로 재하되는 설계트럭 수의 증가에 따라 과도한 하중효과가 반영되는 것을 방지하기 위하여 설계기준 에서 규정하고 있는 다차로재하계수를 적용하였다 (Table 1).

유한요소해석 모델은 이 연구에서 대상으로 하는 가 장 일반적인 형식인 철근콘크리트 바닥판을 모사하며,

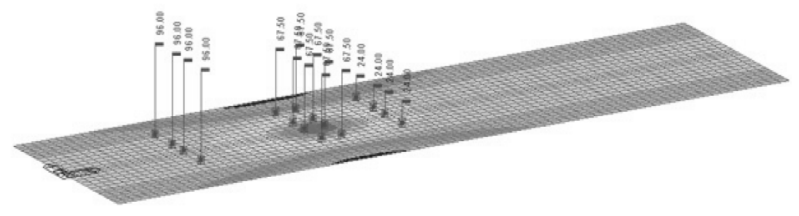

Fig. 1. Example of finite element analysis model

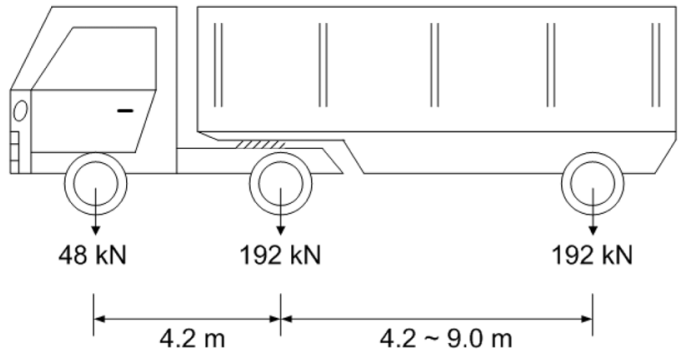

(a) DB 24

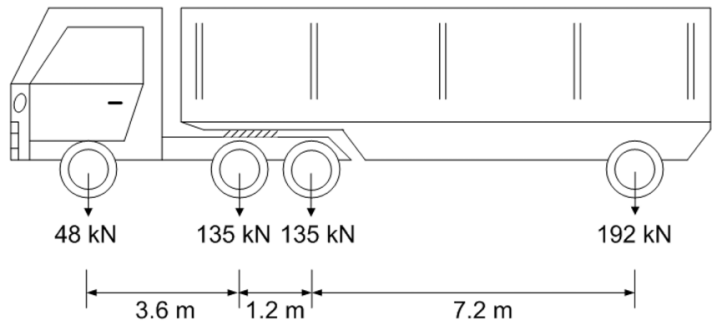

(b) KL-510

Fig. 2. Comparison of the design trucks

Table 1. Multiple presence factors ${ }^{1)}$.

\begin{tabular}{c|c}
\hline Number of loaded lanes & Multiple presence factors \\
\hline \hline 1 & 1.0 \\
\hline 2 & 0.9 \\
\hline 3 & 0.8 \\
\hline 4 & 0.7 \\
\hline$>5$ & 0.65 \\
\hline
\end{tabular}

장지간 바닥판의 경계인 거더 간격 $4 \mathrm{~m}^{11)}$ 이상부터 7 $\mathrm{m}$ 까지의 범위를 대상으로 구성하여 도로교설계기준 (한계상태설계법)에 따라 요구되는 최대단면력과 처짐 기준을 충족하는 최소두께를 구하기 위한 반복해석 과 정에 활용하였다.

한편, 유한요소해석은 범용 구조해석 프로그램인 MIDAS CIVIL LSD을 사용하여 수행되었다.

\section{3. 한계상태를 고려한 최소두께}

도로교설계기준(한계상태설계법)(이하 설계기준)에 서는 구조물의 정상적인 기능 수행 여부를 4 가지 한계 상태로 구분하여 검토하도록 제시하고 있으나, 철근콘 크리트 바닥판에 대해서는 피로한계상태와 극단상황 한계상태 조합에 대하여 검토하지 않아도 된다고 규정 하고 있다. 따라서 여기서는 극한한계상태와 사용한계 상태를 고려하였으며 장지간 바닥판을 대상으로 하므 로 경험적 설계법은 제외하였다. 


\section{1. 극한한계상태를 고려한 최소두께}

설계기준에서 제시하는 교량 바닥판에 대한 전통적 설계법에서 바닥판은 일방향 휨부재로 설계되며, 펀칭 전단에 대해 저항할 수 있어야 한다. 설계법에 따른 결 과를 비교한 선행연구 ${ }^{12)}$ 에서도 소개된 바와 같이, 설계 기준에서는 보다 사실적으로 콘크리트의 재료특성을 반영한 설계를 위하여 휨설계 시 포물선과 직선으로 구성된 응력-변형률 곡선 모델을 제공하고 있다(Fig. 3). 이 때 포물선 구간 상승 곡선부의 형상 지수 $n$ 은 식 (1), 최대응력 도달 시점에서의 변형률 $\varepsilon_{c o}$ 는 식 (2) 그리고 극한변형률 $\varepsilon_{c u}$ 는 식 (3)과 같이 정의된다.

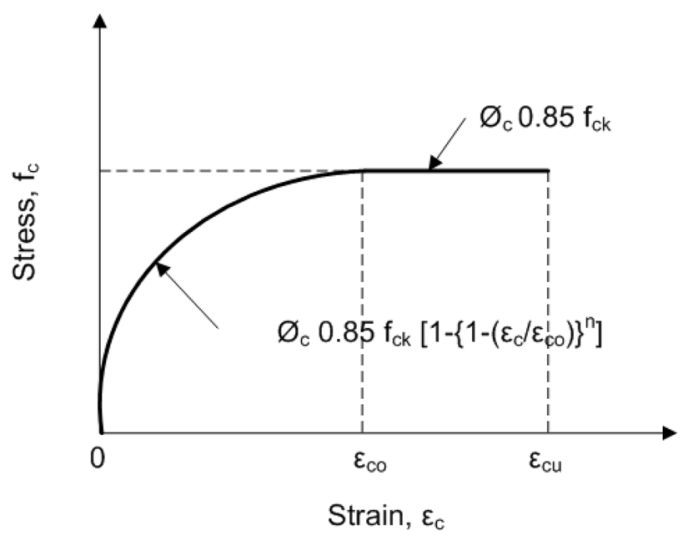

Fig. 3. The stress-strain curve of concrete ${ }^{12)}$.

$$
\begin{aligned}
& n=2.0-\left(\frac{f_{c k}-40}{100}\right) \leq 2.0 \\
& \varepsilon_{c o}=0.002+\left(\frac{f_{c k}-40}{100,000}\right) \geq 0.002 \\
& \varepsilon_{c u}=0.0033-\left(\frac{f_{c k}-40}{100,000}\right) \leq 0.0033
\end{aligned}
$$

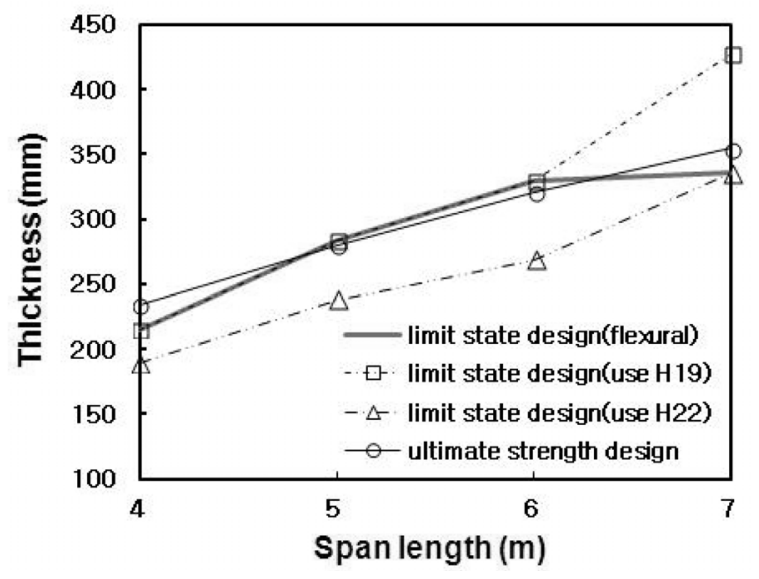

Fig. 4. Minimum thickness for flexural design
앞의 2장에서 수행한 유한요소해석을 통하여 얻어진 최대휨모멘트에 저항할 수 있는 최소두께를 구하는 설 계 과정에서 콘크리트의 설계기준 압축강도를 $30 \mathrm{MPa}$ 로 가정하면, 위의 식들에 대해 각각 $n$ 은 $2.0, \varepsilon_{c o}$ 는 0.002 및 $\varepsilon_{c u}$ 는 0.0033 이며, 콘크리트의 재료계수 $\phi_{c}$ 는 0.65 의 값을 사용하여 Fig. 4 와 같이 지간별로 휨 성능을 확보하 기 위한 바닥판의 최소두께를 얻을 수 있다. 한편, 실제 철근의 배근 시에는 철근 간격에 대한 규정을 고려하여 설계에서 요구하는 값 이상으로 하여야 하므로 실제 배 근량과 설계요구량의 차이는 사용하는 철근의 직경에 따라 달라지게 된다. 따라서 최소두께는 일반적인 두 종 류의 철근을 사용하는 경우에 대해 나타내었으며 강도 설계법에 따라 도출된 결과와와도 비교하였다. 항복강도 $400 \mathrm{MPa}$ 의 $\mathrm{H} 19$ 철근을 사용하는 경우의 두께는 약 220 $\mathrm{mm} \sim 430 \mathrm{~mm}$ 의 범위로서 $\mathrm{H} 22$ 를 사용할 때인 약 190 $\mathrm{mm} \sim 340 \mathrm{~mm}$ 에 비하여 다소 크게 요구되는 것으로 나 타났다. 이는 전자가 설계요구량에 가까운 배근이 가능 하기 때문이다. 따라서 경제성과 안전성을 동시에 고려 할 때 H19를 사용한 두께를 휨에 저항하기 위한 최소두 께로 선정하되 지간 $7 \mathrm{~m}$ 일 때는 기존 중소지간 바닥판 을 대상으로 제안된 최소두께식을 연장하여 계산한 값 인 $410 \mathrm{~mm}$ 보다 크게 되므로 이에 한하여 H22를 사용할 때 요구되는 두께인 약 $340 \mathrm{~mm}$ 를 사용하였다. 강도설계 법에 따른 선행 연구에서도 지간 $6 \mathrm{~m}$ 까지 $\mathrm{H} 19$, 지간 7 $\mathrm{m}$ 에 대해서 $\mathrm{H} 22$ 를 사용하였다. 휨 성능을 확보하기 위 한 바닥판의 최소두께는 설계법의 변화에 따른 큰 차이 없이 유사한 수준으로 계산되었다.

펀칭전단에 대한 저항 성능을 확보하기 위한 최소두 께는 설계기준에서 제시하는 전단철근이 없는 슬래브 부재의 펀칭전단강도 평가식과 2장에서 수행한 유한요 소해석을 통해 구한 최대전단력의 값을 이용하여 계산 하였다. 즉, 하중효과에 의해 유발되는 최대전단응력에 대한 식 (4)에 유한요소해석으로부터 구한 최대전단력 을 대입하면 유효높이만이 변수로 남게 되며, 펀칭전 단강도 평가식 (5)에 대해 유효높이만을 제외한 다른 변수를 가정하고 이 두 식에 의한 값이 동일한 결과를 나타내도록 유효높이를 결정한 후 피복두께를 더하여 펀칭전단에 저항하는 최소두께를 결정하였고, 이를 Fig. 5에 나타내었다.

$$
v_{u}=\frac{V_{u}}{u_{i} d}
$$

여기서 $v_{u}$ 는 최대전단응력, $V_{u}$ 는 최대전단력, $u_{i}$ 는 위험단면의 둘레길이로서 재하면으로부터 유효높이의 


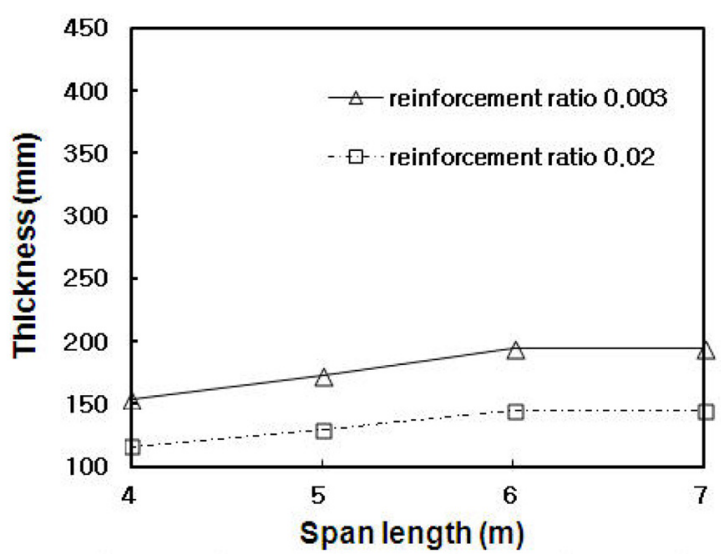

Fig. 5. Minimum thickness for punching shear design

2배 떨어진 거리에서 측정한 길이이며, $d$ 는 유효높이 이다.

$$
v_{c d}=0.85 \phi_{c} \kappa\left(\rho_{l} f_{c k}\right)^{1 / 3}-0.10 f_{n}
$$

여기서 $v_{c d}$ 는 전단철근이 없는 슬래브의 설계펀칭전

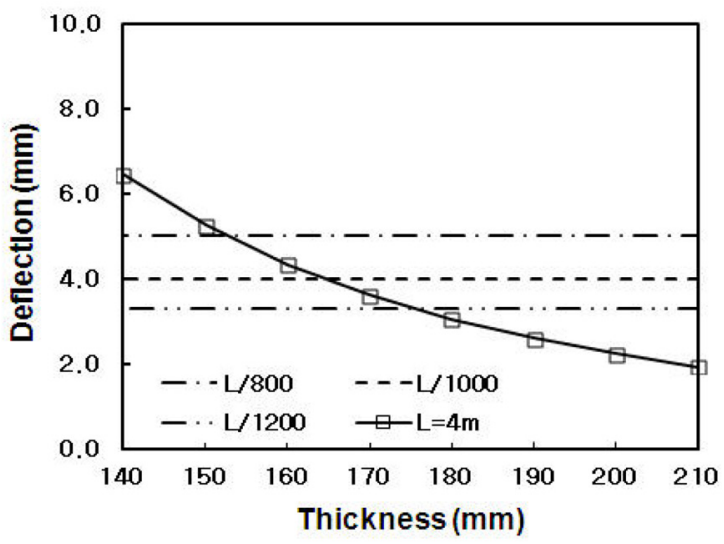

(a) span length : $4 \mathrm{~m}$

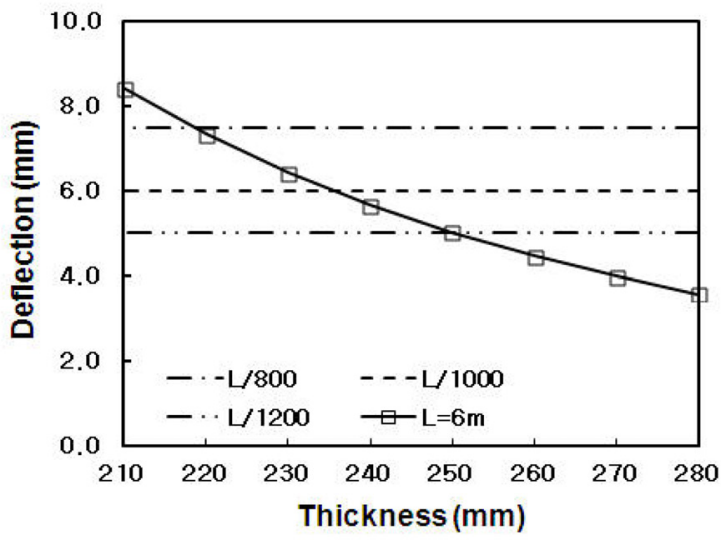

(c) span length : $6 \mathrm{~m}$
단강도로서 $\left(0.4 \phi_{c} f_{c t k}-0.10 f_{n}\right)$ 보다 크거나 같아야 하며, $f_{c k}$ 와 $f_{c t k}$ 는 각각 콘크리트의 설계압축강도와 인장강도이다. $\kappa(=1+\sqrt{200 / d})$ 는 유효높이의 함수 로 표현된 계수로서 2.0 보다 클 수 없다. $\rho_{l}$ 은 철근비 로서 교축 및 교축직각 방향에 대해 곱한 값의 제곱근 으로 고려하며, 최대한계는 설계기준에서 제한하는 값 인 0.02 , 최소한계는 등방배근하는 경험적설계법과 동 일한 수준인 0.003 으로 가정하였다. $f_{n}$ 은 프리스트레 스 힘 등에 의해 단면에 유발되는 압축력이므로 고려 되지 않았다. 펀칭전단에 저항하기 위한 최소두께는 $200 \mathrm{~mm}$ 를 넘지 않는 수준으로서 휨에 저항하기 위해 필요한 두께보다 작게 계산되었는데 이는 정적 펀칭전 단강도 평가식에 기반한 결과이다.

\section{2. 사용한계상태를 고려한 최소두께}

사용한계상태에 대하여 설계기준에서는 응력 한계, 균열과 처짐을 제한하기 위한 규정을 제시하고 있다. 여기에서는 철근배근간격 등 바닥판 설계를 위한 제반

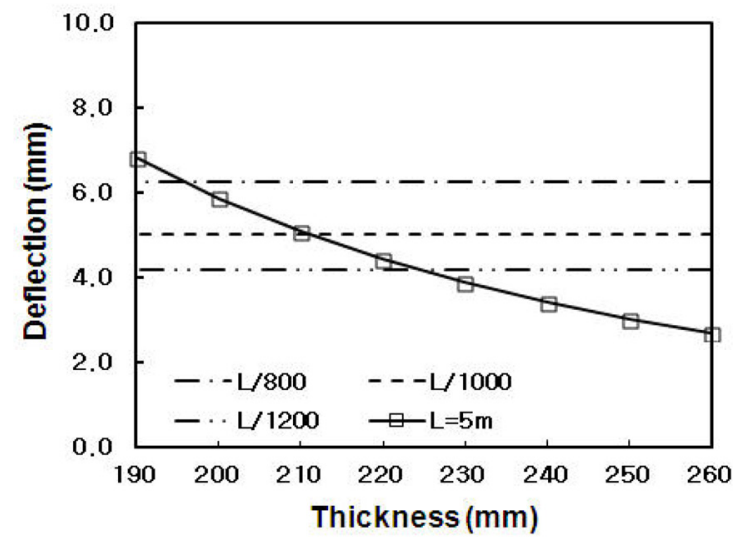

(b) span length : $5 \mathrm{~m}$

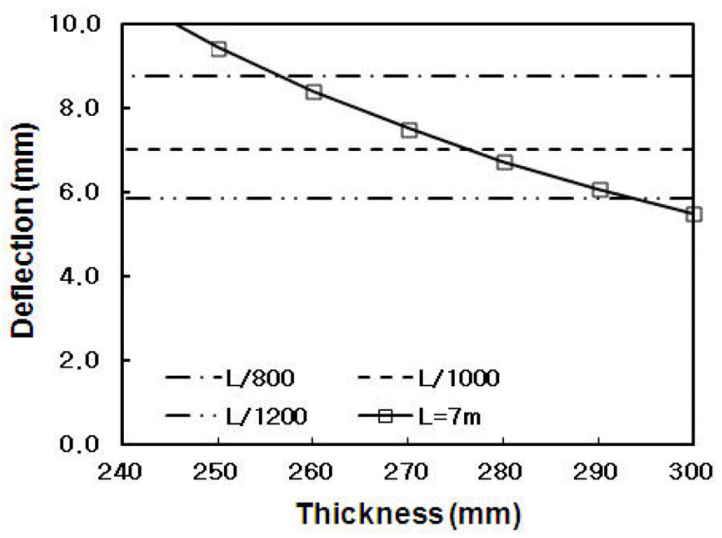

(d) span length : $7 \mathrm{~m}$

Fig. 6. Deflections according to the deck thickness 
규정을 준수하는 것을 전제로 하므로 간접 균열 제어 를 위한 조건을 충족하며, 사용하중조합에 의하여 유 발되는 철근의 인장응력이 항복강도의 $80 \%$ 를 초과하 지 않는 것으로 가정하였다. 따라서 사용한계상태에 대하여 처짐 제한을 충족하기 위한 최소두께를 구하였 다. 이를 위하여 유한요소모델에서 바닥판 두께를 변 화시켜가며 반복 해석을 수행하였으며, 처짐값이 설계 기준에서 제시하는 처짐 제한인 식 (6)과 일치할 때의 두께를 구하였다. 이러한 과정을 바닥판 지간별로 Fig. 6에 나타내었다.

$$
\begin{aligned}
\delta_{\max } & =L / 800(\text { 사람의 통행이 없는경우) } \\
& =L / 1000(\text { 제한된 수의 사람이통행 }) \\
& =L / 1200 \text { (많은 사람이 통행하는 경우) }
\end{aligned}
$$

여기서, $\delta_{\max }$ 는 설계기준에서 제시하는 최대 처짐 제 한값(m)이며 $L$ 은 바닥판 받침부 중심간 거리 $(\mathrm{m})$ 이다.

바닥판의 처짐은 예상할 수 있는 바와 같이 바닥판 의 지간이 클수록, 동일 지간 내에서는 바닥판의 두께 가 얇을수록 증가되는 경향을 보인다. 처짐제한은 식 (6)에서 보는 바와 같이 보행자의 통행 조건에 따라 세 가지로 구분되므로 바닥판 지간별로 세 가지 기준에 대한 최소두께가 구해진다. 지간 $6 \mathrm{~m}$ 의 예를 들면, 보 행자 통행이 없는 경우에 처짐기준을 총족하는 최소두 께는 약 $220 \mathrm{~mm}$, 제한된 수의 사람이 통행하는 경우에 는 약 $235 \mathrm{~mm}$ 이며 많은 사람이 통행하는 경우에 대해 서는 약 $250 \mathrm{~mm}$ 와 같이 증가되는 경향을 볼 수 있다. 이와 같은 결과는 균열 발생을 고려하지 않은 것으로 서 교축 및 교축직각 방향 강성을 동일한 것으로 가정 하여 얻어진 값이다. 그러나 선행 연구 결과에에 따르면 균열 발생에 따라 두 방향의 강성이 감소되어 크기가 달라지며, 이를 고려한 이방성 해석에 의하면 처짐이

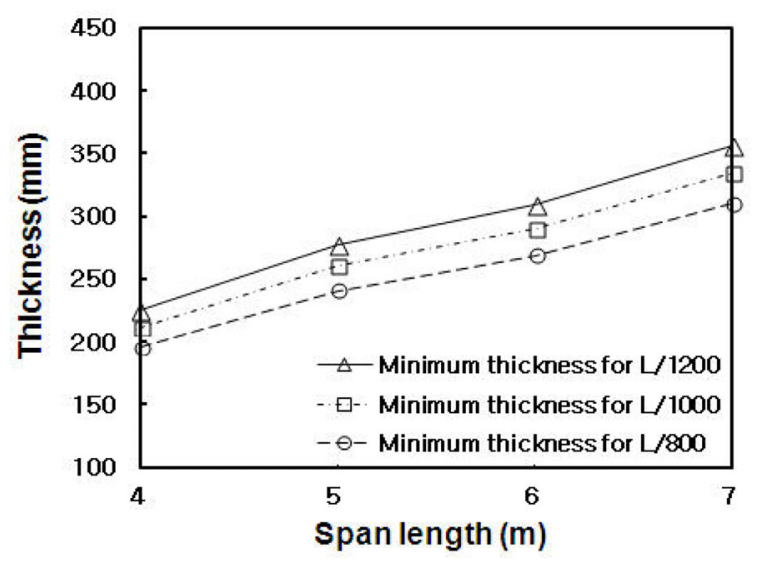

Fig. 7. Minimum thickness for deflection limits

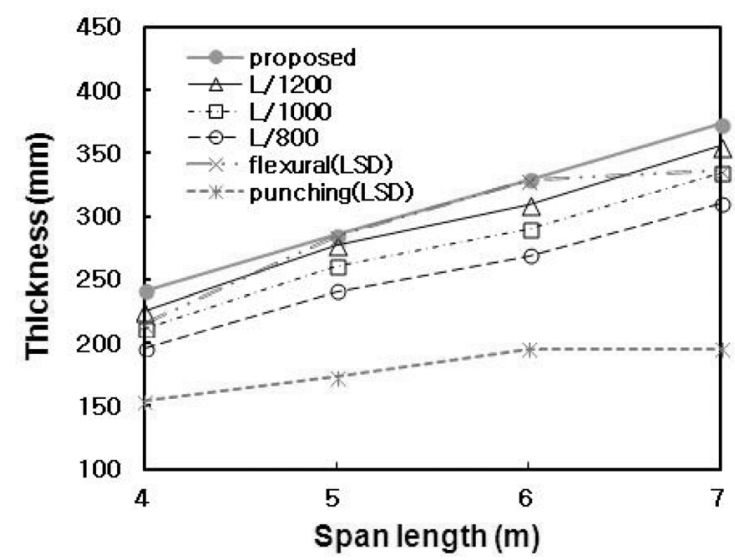

Fig. 8. Comparison of the thickness for limit states

평균적으로 약 $24 \%$ 정도 증가되는 것으로 보고되었다. 따라서 선행연구에서 바닥판 지간별로 계산된 이방성 도를 사용하여 보정된 값을 사용한계상태를 고려한 최 소두께로 선정하였으며 이를 Fig. 7에 나타내었다. 이 로부터 앞서 예시한 지간 $6 \mathrm{~m}$ 의 바닥판에 대해 각각의 처짐기준을 만족하는 두께가 약 $270 \mathrm{~mm}, 290 \mathrm{~mm}$ 및 $310 \mathrm{~mm}$ 로 상향되어 있는 것을 확인할 수 있다.

\section{4. 최소두께의 비교}

극한한계상태와 사용한계상태에 대하여 3장에서 검 토한 바닥판의 최소두께를 비교하고, 바닥판 지간별로 지배적인 한계상태를 충족할 수 있는 두께를 구하여 최소두께식을 제안하였다.

각 한계상태에 따른 바닥판 두께를 비교한 Fig. 8을 통해 볼 때 전반적으로 극한한계상태에 대해 휨에 대 한 저항성능을 확보하기 위해 필요한 두께와 사용한계 상태에 대해 처짐 제한을 충족하기 위해 필요한 두께 가 최소두께를 결정하는 주요 원인으로 고려됨을 알 수 있다. 즉, 지간 $4 \mathrm{~m}$ 와 $7 \mathrm{~m}$ 에 대하여 처짐 제한을 총 족하기 위한 두께가 가장 크게 요구되었으며, 지간 5 $\mathrm{m}$ 와 $6 \mathrm{~m}$ 에서는 휨 설계를 통하여 결정되는 두께가 가 장 큰 것으로 나타났다. 각 바닥판 지간별로 가장 큰 두께가 요구되는 한계상태를 검토하고 이 때의 값들에 대해 직선회귀분석을 실시하여 결정계수가 0.97 수준 의 관계식을 도출한 후, 모든 경우에 대해 안전측의 결 과를 나타내도록 이동시켜 아래의 식 (7)과 같은 최소 두께식을 결정하였다.

$$
t_{\text {min }}=44 L+65
$$

여기서 $t_{\mathrm{min}}$ 은 바닥판의 두께 $(\mathrm{mm}), L$ 은 바닥판의 


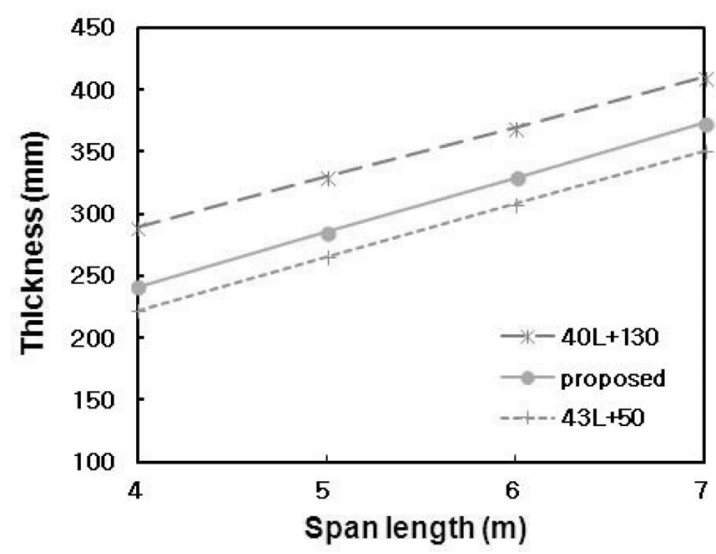

Fig. 9. Comparison of the minimum thickness

지간 $(\mathrm{m})$ 으로서 $4 \mathrm{~m} \sim 7 \mathrm{~m}$ 의 범위이다. 한편, 극한한 계상태에 대한 검토에서 실제 바닥판의 대표적인 손상 형태로 알려진 펀칭전단에 저항하기 위해 필요한 두께 는 휨에 대한 저항성능을 확보하기 위해 필요한 두께 보다 매우 작게 나타났으며, 처짐에 대한 사용성을 확 보하기 위해 필요한 두께보다도 작게 나타나 최소두께 의 결정에 영향을 미치지 못하였다. 이는 한계상태설 계법으로 설계된 바닥판이 펀칭전단 손상에 대해 안전 하다는 의미가 아니며, 설계기준에서 제시하는 펀칭전 단평가식이 정적 거동에 기초하므로 실제 바닥판의 펀 칭전단 거동에 영향을 미치는 피로와 환경적 영향을 고려하지 못하기 때문일 것이다.

제안된 바닥판의 최소두께는 기존 도로교설계기준 및 선행연구의 결과식과 비교하여 Fig. 9에 나타내었 다. 제안식 (7)에 의하여 계산되는 바닥판의 최소두께 는 지간에 따라 증가되며 $4 \mathrm{~m} \sim 7 \mathrm{~m}$ 에 대해 $241 \mathrm{~mm}$ $373 \mathrm{~mm}$ 의 범위의 결과를 보여준다. 이 결과는 선행 연구 ${ }^{5}$ 와 비교할 때 $6.3 \% \sim 8.6 \%$ 큰 값으로서 평균적 으로 약 $20.5 \mathrm{~mm}$ 정도 증가된 두께를 요구하고 있다. 그러나, 선행 연구에서 제시한 $43 L+50$ 의 식은 이전 도 로교설계기준의 규정 하에서 사용성을 만족하기 위해 필요한 두께로부터 도출한 것이므로 한계상태설계법 으로 설계할 때 기존 도로교설계기준보다 더 큰 바닥 판 두께가 요구되는 것을 의미하는 것은 아니다. 특히 3장의 Fig. 4에서 휨 성능을 확보하기 위해 필요한 두 께가 설계법과 관계없이 거의 유사하게 나타났음을 감 안할 때 선행연구에서도 이 부분을 고려하였다면 매우 흡사한 결과가 도출되었을 것으로 생각된다. 한편, 기 존 도로교설계기준의 최소두께식 $40 L+130$ 과 비교할 때 제안식은 약 $87 \%$ 수준으로서 평균적으로 약 $40 \mathrm{~mm}$ 정도 얇은 두께가 요구되는 것으로 나타났으며, 지간 범위에 대해 $83 \% \sim 91 \%$ 로서 지간이 길어짐에 따라
점차 그 차이가 줄어드는 경향을 보였다.

\section{5. 결론 및 고찰}

이 연구에서는 기존 DB 24 하중에 비해 크기가 증 가된 KL-510 하중의 효과를 유한요소해석을 통하여 구하였으며, 도로교설계기준(한계상태설계법)의 제반 규정에 따라 한계상태에 대해 검토하여 장지간 바닥판 의 설계 시 참고할 수 있는 최소두께를 제안하였다. 이 과정을 통하여 다음과 같은 결론을 도출하였다.

1) 극한한계상태에 대한 검토에서 휨에 대한 저항성 능을 확보하기 위한 두께는 하중 크기의 증가에도 불 구하고 DB 24 하중을 적용한 기존 설계기준의 결과와 유사한 수준으로 나타났다. KL-510 하중 모델은 DB 24 하중에 비해 총하중은 증가하였으나 하중계수나 다 차로계수가 감소되어 휨 설계에 영향을 미치는 하중효 과가 유사하게 도출된 것으로 판단된다.

2) 한편 실제 바닥판의 손상 형태로 알려진 펀칭전 단에 저항하기 위해 필요한 두께는 정적 펀칭전단강도 평가식에 기초하여 계산되었으므로 휨 설계에 의해 결 정되는 두께보다 매우 작게 요구되었다. 추후 국내의 공용 여건을 반영한 피로 및 환경적 영향을 포함하여 적절한 평가를 수행할 수 있는 방법이 요구된다.

3) 사용한계상태에 대하여 처짐 제한 기준을 충족하 기 위해 필요한 두께를 유한요소모델을 이용한 반복해 석을 통하여 구하고, 극한한계상태에 대한 저항 성능 을 확보하기 위해 필요한 두께와 비교하였다. 차량 통 행을 고려하는 경우에 처짐 제한을 충족하기 위해 필 요한 두께가 휨 설계에 의해 결정되는 두께보다 큰 경 우가 다수 발생되었으므로 최소두께 결정에 영향을 미 치는 요소로 고려되었다.

4) 극한한계상태 및 사용한계상태에 대한 저항성능 을 확보하기 위해 필요한 두께를 비교하여 검토한 모 든 경우에 대해 안전측의 결과를 제공하는 최소두께식 을 제안하였다. 제안식은 기존 설계기준 조항에 따른 사용성만을 고려한 선행연구와 비교할 때 평균적으로 약 $7.5 \%$ 증가된 두께를 요구하는 것으로 비교되었으나 안전을 고려한 휨 설계에 따른 요구를 포함한다면 유 사한 수준이며, 기존 도로교설계기준의 최소두께식과 비교하면 약 $13 \%$ 감소된 결과를 제공한다.

감사의 글: 이 논문은 2013년도 서일대학교 교내연 구비의 지원으로 작성되었습니다. 이에 감사드립니다. 


\section{References}

1) Ministry of Land, Transport and Maritime Affairs, "Korean Highway Bridge Design Code(Limit State Design)”, Korea Road and Transportation Association, 2012.

2) Ministry of Land, Transport and Maritime Affairs, "Korean Highway Bridge Design Code", Korea Road and Transportation Association, 2010.

3) E. S. Hwang, "Development of Vehicular Load Model using Heavy Truck Weight Distribution(I)-Data Collection and Estimation of Single Truck Weight", Journal of the Korean Society of Civil Engineers, Vol.29, No.3A, pp. 189-197, 2009.

4) E. S. Hwang, "Development of Vehicular Load Model using Heavy Truck Weight Distribution(II)-Multiple Truck Effects and Model Development", Journal of the Korean Society of Civil Engineers, Vol.29, No.3A, pp. 199-207, 2009.

5) H. H. Hwang and C. B. Joh, "Minimum Design Thickness of RC Deck Slabs for a composite Two-Girder Bridge Considering Serviceability and Constructability", Journal of the Korean Society of Civil Engineers, Vol. 25, No. 6A, pp. 981 988, 2005.

6) H. H. Hwang, C. B. Joh, J. W. Kwark and Y. W. Lee, "Minimum Design Thickness of Prestressed Concrete Deck Slabs for composite Two-Girder Bridges", Journal of the Korean Society of Civil Engineers, Vol. 26, No. 1A, pp. 183 190, 2006.
7) H. J. Lee and C. H. Jung, "Minimum Thickness of Long Span Bridge Deck Slabs for Two-Girder Bridges", Journal of the Korean Society of Civil Engineers, Vol. 27, No. 3A, pp. 303 311, 2007.

8) H. H. Hwang, C. B. Joh, H. J. Yoon and B. S. Kim, "Punching and Fatigue Behavior of Long-Span Prestressed Concrete Deck Slabs", Engineering Structures, Vol. 32, Issue. 9, pp. 2861 2872, 2010.

9) C. H. Jung and H. J. Lee, "Static and Fatigue Behavior of the Long Span Precast Decks", Journal of the Korean Society of Civil Engineers, Vol. 23, No. 4A, pp. 721 731, 2003.

10) W. J. Park and H. H. Hwang, "Prediction of Failure Mode Under Static Loading in Long Span Bridge Deck Slabs by FEM", Journal of the Korea Institute for Structural Maintenance and Inspection, Vol. 16, No. 4, pp. 52 59, 2012.

11) Korean Society of civil Engineers, "Commentary of Korean Highway Bridge Design Code", 2008.

12) J. W. Park, H. H. Hwang, S. O. Kang, K. S. Cho and W. J. Park, "Evaluation for Relative Safety of RC Slab Bridge of Applying Limit State Design Code on Korean Highway Bridge", Journal of the Korean Society of Safety, Vol. 28, No. 5, pp. 41 48, 2013. 